\title{
EFFECT OF INCORPORATION LEVELS OF OAT AND GREEN PEA FLOUR ON THE PROPERTIES OF AN EXTRUDED PRODUCT AND THEIR OPTIMIZATION
}

\author{
S.A.WANI and P. KUMAR* \\ Department of Food Engineering and Technology, Sant Longowal Institute of Engineering and Technology, \\ Longowal 148106. India
}

(Received: 29 September 2014; accepted: 27 January 2015)

\begin{abstract}
An extruded product was made based on oats and dried green pea using central composite rotatable design. Effects of incorporation level of oat flour (OF, 15.86 to $44.14 \%$ ) and dried green pea flour (DGPF, 7.93 to $22.07 \%$ ) on the physical and functional characteristics of extruded products based on composite flour were studied using response surface methodology. Second order polynomial equation was used to describe the effect of OF and DGPF on lateral expansion (LE), bulk density (BD), water solubility index (WSI), water absorption index (WAI), and hardness (HD). Results indicated that OF had negative effect on LE, while positive effect on BD, WSI, WAI, and HD. On increasing DGPF, LE and WSI increased, but it had negative effect on BD, WAI, and HD. Numerical optimization resulted in $41.91 \%$ OF and $7.93 \%$ DGPF to produce acceptable extrudates. The results suggest that oats and dried green pea flour can be extruded with rice flour and corn flour into an acceptable snack food.

Keywords: oat, pea, extrusion, functional properties, optimization
\end{abstract}

Cereals are generally used as major sources of raw materials in extruded snack products because of their good expansion characteristics. Characteristics like expansion, hardness, and density are important parameters in terms of the consumer acceptability of an extruded snack product as well as its functional properties (JAMORA et al., 2002).

Oat (Avena sativa) has attracted a great deal of commercial attention and is a subject of considerable research efforts due to its nutritional value (Peterson, 2001). Oat has been recognised as a healthful and nutritious cereal containing high concentration of soluble fibre and dense nutrients. $\beta$-glucan has been shown to have effects on glycaemic, cholesterol, and insulin responses to foods and also to the insulin (WANI et al., 2014). CHANG and co-workers (2002) found that extrudates prepared from mixtures of cassava starch and Novelose or oat fibre have hypocholesterolaemic properties.

Peas (Pisum sativum) are widely cultivated worldwide and easily available as dry products (RAVINDRAN et al., 2011). Peas are rich sources of lysine and can complement cereals complying with the FAO reference guide for protein and amino acid intake (FAO, 2007). FRIAS and co-workers (2011) have reported negligible trypsin inhibitor activity in pea during extrusion process at $129^{\circ} \mathrm{C}, 135^{\circ} \mathrm{C}$, and $142{ }^{\circ} \mathrm{C}$, which indicated that these temperature conditions could be considered adequate for the manufacturing of novel pea-derived products with high nutritive value. SUdHA and LeELAVATHI (2012) investigated that dehydrated green pea flour (DGPF) could be an alternative ingredient for the production of pasta, which is highly nutritious with natural green colour.

* To whom correspondence should be addressed. Phone: +91-1672-253399(O); fax: +91-1672-280057; e-mail: pradyuman@sliet.ac.in 
By considering the facts that oats are highly nutritious and rich sources of dietary fibre and peas are rich in protein, an extruded product can be developed that is nutritionally dense. Therefore, the aim of this research was to investigate the effect of different proportions of OF and DGPF on the physical and functional properties of extruded products. The target was also to optimize the proportion of OF and DGPF for the production of a quality extruded product.

\section{Materials and methods}

Dried green pea, oats, rice, and corn flours were bought from local market Longowal, Sangrur, Punjab. Extrusion of samples was done using a co-rotating twin-screw extruder (BTPL, India). The die diameter, barrel temperature, and feed moisture used in this study was $4 \mathrm{~mm}$, $110{ }^{\circ} \mathrm{C}$, and $12 \%$ wet basis, respectively. The extrudates were cooled at room temperature for 30 min, packaged in LDPE bags and stored at ambient condition until analysed.

Response surface methodology was adopted in the design of experimental combinations. The levels of each variable were established according to literature data (HoLGUín-Acuña et al., 2008; Balasubramanian et al., 2012) and preliminary trials. Composite flour (rice flour and corn flour of the ratio 80:20) as a base material was used according to the preliminary trials and literature data for extrusion cooking. In the present study composite flour was partly replaced by OF (15.86 to $44.14 \%$ ) and DGPF (7.93 to $22.07 \%$ ). A total of 13 experiments were carried out as shown in Table 1 for production of extruded products.

The determination of moisture content, ash, protein (Kjeldahl method, protein factor: 6.25), fat, and total dietary fibre were performed as per AOAC (2005). The carbohydrate content was calculated by difference.

\subsection{Lateral expansion}

The lateral expansion of 15 random samples for each extruded products was calculated as described by MENG and co-workers (2010).

$$
\mathrm{LE}=\frac{\text { (diameter of extrudate-diameter of die opening) }}{\text { diameter of die opening }} \times 100
$$

\subsection{Bulk density $(B D)$}

Bulk density was calculated according to the method of AlvarEz-MARTinEz and co-workers (1988). About 10 pieces of extrudates were used to determine the bulk density.

$$
\mathrm{BD}\left(\mathrm{g} \mathrm{cm}^{-3}\right)=\frac{4 \mathrm{~m}}{\pi \mathrm{d}^{2} \mathrm{~L}}
$$

where $\mathrm{m}$ is mass $(\mathrm{g})$ of an extrudate with $\mathrm{L}(\mathrm{cm})$ length and $\mathrm{d}(\mathrm{cm})$ diameter.

\subsection{Water absorption index (WAI) and water solubility index (WSI)}

WAI and WSI were estimated by the method described by ANDERSON (1982). About $2.5 \mathrm{~g}$ sample was dispersed in $25 \mathrm{~g}$ distilled water and it was stirred for $30 \mathrm{~min}$ using a glass rod. This dispersion was then rinsed and tarred into centrifuge tubes, then centrifuged at $3000 \mathrm{~g}$ 
for $15 \mathrm{~min}$. The supernatant was decanted for determination of its solid content and the sediment was weighed.

$\mathrm{WAI}(\%)=($ Weight of sediment $) /($ weight of dry solids $) \times 100$

WSI $(\%)=\frac{\text { Weight of dissolved solids in supernatant }}{\text { weight of dry solids }} \times 100$

Table 1. Effect of independent variables on physical and functional properties of extruded product

\begin{tabular}{|c|c|c|c|c|c|c|c|c|c|}
\hline \multirow[t]{2}{*}{ Runs } & \multicolumn{2}{|c|}{ Coded levels } & \multicolumn{2}{|c|}{ Actual levels } & \multicolumn{5}{|c|}{ Product responses } \\
\hline & $\mathrm{X}_{1}$ & $\mathrm{X}_{2}$ & $\begin{array}{l}\text { OF } \\
(\%)\end{array}$ & $\begin{array}{c}\text { DGPF } \\
(\%)\end{array}$ & $\begin{array}{l}\text { LE } \\
(\%)\end{array}$ & $\begin{array}{c}\mathrm{BD} \\
\left(\mathrm{g} \mathrm{cm}^{-3}\right)\end{array}$ & $\begin{array}{l}\text { WSI } \\
(\%)\end{array}$ & $\begin{array}{l}\text { WAI } \\
(\%)\end{array}$ & $\begin{array}{c}\text { Hardness } \\
\text { (N) }\end{array}$ \\
\hline 1 & +1 & +1 & 40 & 20 & 156.7 & 0.173 & 18.12 & 4.5 & 13.4 \\
\hline 2 & +1 & -1 & 40 & 10 & 161 & 0.149 & 12.01 & 5.12 & 13.21 \\
\hline 3 & -1 & +1 & 20 & 20 & 163.9 & 0.135 & 13.02 & 5.1 & 13.12 \\
\hline 4 & -1 & -1 & 20 & 10 & 176.3 & 0.18 & 15 & 6.4 & 11.39 \\
\hline 5 & +1.414 & 0 & 44.14 & 15 & 172 & 0.169 & 22.21 & 4.34 & 14.33 \\
\hline 6 & -1.414 & 0 & 15.86 & 15 & 162.9 & 0.139 & 11.99 & 5.09 & 13.02 \\
\hline 7 & 0 & +1.414 & 30 & 22.07 & 174.5 & 0.2 & 20 & 6.4 & 13.99 \\
\hline 8 & 0 & -1.414 & 30 & 7.93 & 154 & 0.19 & 17.04 & 6.02 & 15.6 \\
\hline 9 & 0 & 0 & 30 & 15 & 164.4 & 0.142 & 12.8 & 5.29 & 13.35 \\
\hline 10 & 0 & 0 & 30 & 15 & 185 & 0.125 & 18.9 & 5.5 & 14.5 \\
\hline 11 & 0 & 0 & 30 & 15 & 163.8 & 0.14 & 12.67 & 4.99 & 13.19 \\
\hline 12 & 0 & 0 & 30 & 15 & 160 & 0.13 & 9.89 & 5.4 & 11.4 \\
\hline 13 & 0 & 0 & 30 & 15 & 167.02 & 0.13 & 14.69 & 5.35 & 15.89 \\
\hline
\end{tabular}

\subsection{Hardness}

Texture profile analysis (TPA) of all the extruded puffs was performed in triplicate using Texture analyzer (TA-X2Ti, Stable Microsoft System, UK). Hardness (N) of the samples was recorded by analysing the TPA graph using the Texture Exponent 32 software (Stable Microsoft system, UK). Hardness was determined by using an extrudate of about $10 \mathrm{~cm}$ long, which was compressed with a probe three point bend ring with a target mode distance of 3 $\mathrm{mm}$ and trigger force of $5 \mathrm{~g}$.

\subsection{Statistical analysis}

Statistical analysis was conducted using a commercial statistical package, Design-Expert version 6.0.10 (Stat-Ease Inc., Minneapolis, USA). The analyses of extruded samples were conducted in triplicates. Duncan test was used to determine the difference between the means.

\section{Results and discussion}

Table 2 shows the proximate composition of flour samples. A significant difference $(\mathrm{P} \leq 0.05)$ was observed in moisture, ash, crude fibre, protein, and total carbohydrate contents of oats and dried green pea flour. 
Table 2. Proximate composition of rice, corn, oat, and dried green pea flour

\begin{tabular}{lcccc}
\hline Composition (\%) & Rice & Corn & OF & DGPF \\
\hline Moisture & $11.67 \pm 0.1^{\mathrm{a}}$ & $11.57 \pm 0.7^{\mathrm{a}}$ & $8.59 \pm 0.3^{\mathrm{c}}$ & $9.44 \pm 0.3^{\mathrm{b}}$ \\
Ash & $0.88 \pm 1.1^{\mathrm{c}}$ & $1.43 \pm 0.6^{\mathrm{b}}$ & $1.77 \pm 0.1^{\mathrm{b}}$ & $2.74 \pm 0.1^{\mathrm{a}}$ \\
Crude protein & $7.38 \pm 0.9^{\mathrm{d}}$ & $8.86 \pm 0.4^{\mathrm{c}}$ & $13.91 \pm 0.9^{\mathrm{b}}$ & $22.96 \pm 1.4^{\mathrm{a}}$ \\
Crude fat & $1.99 \pm 0.5^{\mathrm{c}}$ & $4.32 \pm 0.3^{\mathrm{b}}$ & $6.35 \pm 0.5^{\mathrm{a}}$ & $1.13 \pm 0.4^{\mathrm{c}}$ \\
Crude fibre & $0.91 \pm 0.7^{\mathrm{c}}$ & $2.00 \pm 1.0^{\mathrm{b}}$ & $2.61 \pm 1.04^{\mathrm{b}}$ & $4.96 \pm 0.3^{\mathrm{a}}$ \\
Total carbohydrate & $88.82 \pm 1.8^{\mathrm{a}}$ & $83.38 \pm 1.1^{\mathrm{b}}$ & $75.34 \pm 0.7^{\mathrm{c}}$ & $68.19 \pm 0.9^{\mathrm{d}}$ \\
\hline
\end{tabular}

a, b, c, d. Figures in a row followed by different superscripts indicate that they are significantly $(\mathrm{P} \leq 0.05)$ different from each other determined by Duncan's tests.

\subsection{Lateral expansion (LE)}

Expansion characteristics of extruded products have an important role in the acceptability of the final product. The range of LE was between 154 and 185\% (Table 1). The regression analysis showed that DGPF had positive linear effect on LE of extruded products, while OF had negative effect on the extruded products. It was observed from the response plot (Fig. 1A) that with the increase in the content of DGPF there was an increase in LE at lower level of OF. When considering the interactive effect of both the OF and DGPF, it resulted a decrease in LE of the extruded product. This may be attributed to the high protein content in pea and high dietary fibre contents in oats. Proteins affect the LE through their ability to influence water distribution in the matrix and through their macromolecular structure that affects the extensional properties of the extruded melts (Moraru \& KoKInI, 2003). OnwUlata and coworkers (2001) investigated the effects of whey protein concentrate and isolate on the extrusion of corn and rice starch and reported a reduction in expansion at higher concentrations of protein. This may be due to the modification in the viscoelastic properties of the dough as a result of competition between the starch and protein fractions for the available water, leading to a delay in starch gelatinization and a lower expansion in the products.
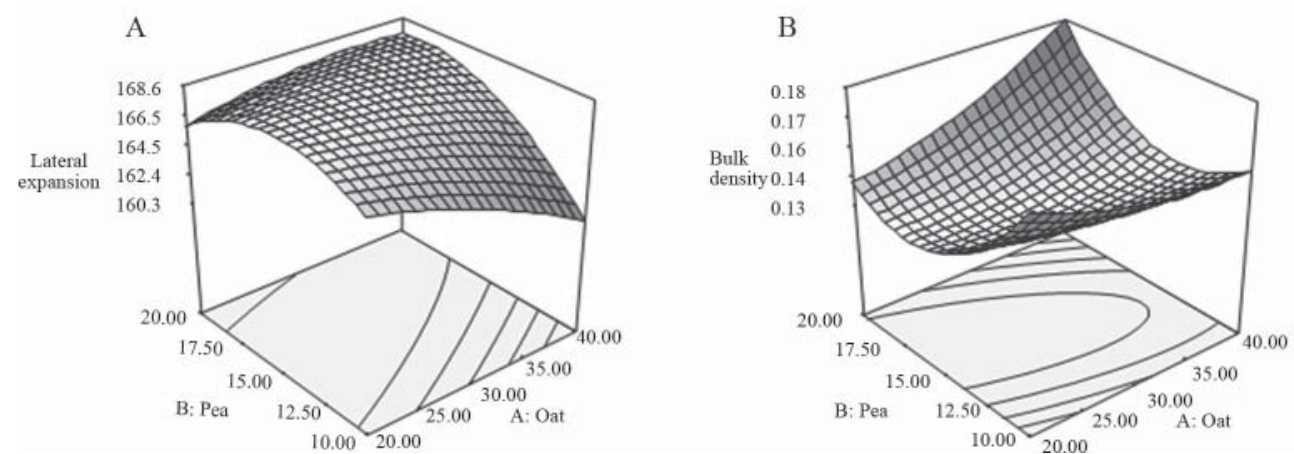

Fig. 1. Response surface plot for (A) lateral expansion (\%) and (B) bulk density $\left(\mathrm{g} \mathrm{cm}^{-3}\right)$ as a function of $\mathrm{OF}$ and DGPF 


\subsection{Bulk density (BD)}

The density of extrudate varied between $0.13-0.20 \mathrm{~g} \mathrm{~cm}^{-3}$ (Table 1), which is similar to chickpea flour snack product $\left(0.130\right.$ and $0.275 \mathrm{~g} \mathrm{~cm}^{-3}$ ) (MeNG et al., 2010) and maize grits extrudates (0.09-0.32 $\left.\mathrm{g} \mathrm{cm}^{-3}\right)$ (ILo et al., 1996). The results of regression analysis showed that DGPF had significant positive $(\mathrm{P} \leq 0.001)$ quadratic effect and OF and DGPF had a significant $(\mathrm{P} \leq 0.05)$ positive interactive effect on $\mathrm{BD}$ of extruded products (Table 3$)$. From the response surface plot (Fig. 1B) it was observed that with increase in the content of OF in the mixture, there is an increase in BD at lower levels of DGPF, while BD decreased with the increase of the content of DGPF at certain levels, thereafter it increased.

Table 3. Results of regression analysis of responses of extruded product

\begin{tabular}{lccccc}
\hline Parameters & $\begin{array}{c}\text { LE } \\
(\%)\end{array}$ & $\begin{array}{c}\text { BD } \\
\left(\mathrm{g} \mathrm{cm}^{-3}\right)\end{array}$ & $\begin{array}{c}\text { WSI } \\
(\%)\end{array}$ & $\begin{array}{c}\text { WAI } \\
(\%)\end{array}$ & $\begin{array}{c}\text { Hardness } \\
(\mathrm{N})\end{array}$ \\
\hline$\beta_{0}$ & 168.04 & 0.133 & 13.79 & 5.30 & 13.66 \\
OF $\left(\mathrm{X}_{1}\right)$ & -1.20 & 0.006 & 2.07 & $0.37 *$ & 0.49 \\
DGPF $\left(\mathrm{X}_{2}\right)$ & 1.53 & -0.000 & 1.03 & -0.17 & -0.04 \\
OF $\left(\mathrm{X}_{1}\right)^{2}$ & -0.64 & $0.006^{* *}$ & 0.83 & -0.34 & -0.35 \\
DGPF $\left(\mathrm{X}_{2}\right)^{2}$ & -2.24 & $0.026^{*}$ & 1.54 & $0.40^{*}$ & 0.20 \\
OF $\times$ DGPF & 2.02 & 0.017 & 2.02 & 0.17 & -0.38 \\
\hline
\end{tabular}

*: Significant at $\mathrm{P} \leq 0.05 ; * *$ : significant at $\mathrm{P} \leq 0.001$

\subsection{Water solubility index (WSI)}

It measures the amount of soluble polysaccharide released from starch granules after addition of excess water (SRIBURI \& HiLl, 2000). In this experiment, the WSI ranged from 9.89 to $22.21 \%$ (Table 1). From the regression analysis report, it was found that OF had a positive linear effect, while DGPF also had a positive linear effect on WSI of the extruded product (Table 3). From the response surface plot of WSI (Fig. 2A), it was observed that with the increase in the content of OF, the WSI value increased at lower values of DGPF, whereas there was also an increase in WSI with the increase in DGPF, at lower values of OF. The behaviour of oats could be attributed to the amount of lipid and dietary fibre present in oats. Some studies have shown that oat starch differs from others by having lower solubility (Paton, 1979). The same results were found in a previous study (Shirani \& Ganesharanee, 2009), where WSI of the extrudates increased $(\mathrm{P} \leq 0.05)$ when protein rich chickpea flour (like green pea flour) incorporation was increased.

\subsection{Water absorption index (WAI)}

In this experiment, the WAI ranged from 4.34 to $6.40 \%$ (Table 1). Similar findings were observed by SHIRANi and GanesharaneE (2009) as 4.09 to $7.79 \%$. The regression analyses for WAI showed that OF had significant $(\mathrm{P} \leq 0.05)$ positive linear effect, whereas DGPF had positive quadratic effect (Table 3). While observing the response surface plot (Fig. 2B), it was found that with the addition of DGPF from 7.93 to $22.07 \%$, a decrease in WAI of extruded product was observed. Similar results were observed by SINGH and co-workers (2007), with addition of pea grits they found a decrease in WAI in the extrusion of rice. They had explained 
that a decrease in WAI was due to the dilution of starch in rice pea blends. On the other hand, the WAI increased with the increase of the content of OF to some level, after it decreased. This increase may be due to $\beta$-glucan present in oat, as the absorption of water is the characteristic feature of fibre supplemented flours (CHAPLIN, 2003). High dietary fibre in oats may interact with water by means of various types of interactions, such as polar, hydrophobic interactions, or hydrogen bonding.
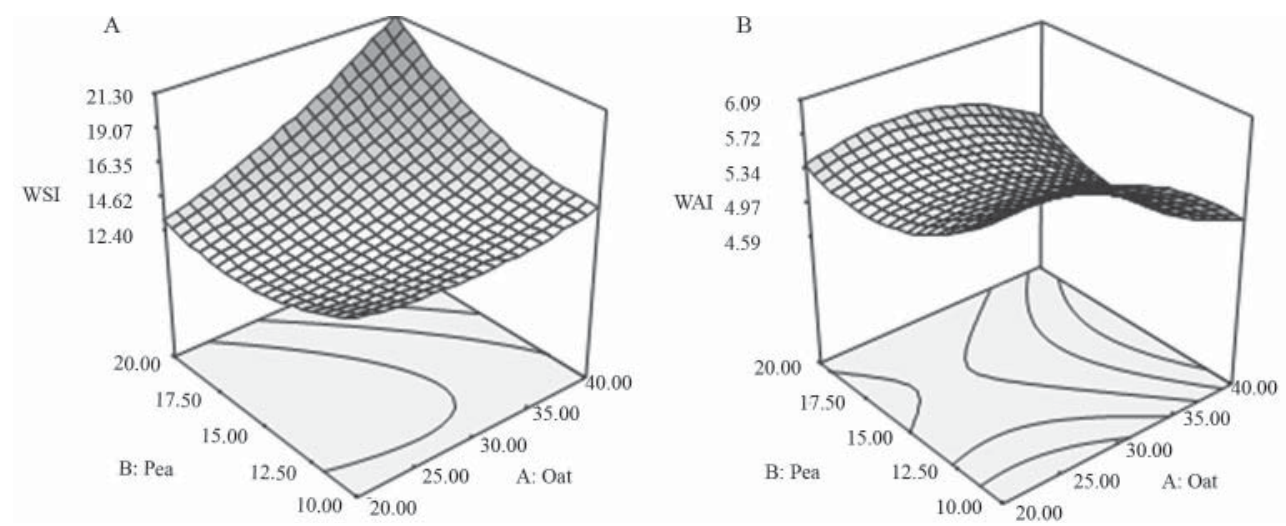

Fig. 2. Response surface plot for (A) WSI (\%) and (B) WAI (\%) as a function of OF and DGPF

\subsection{Hardness (HD)}

The hardness of an extruded product is a sensory perception and is associated with the expansion and cell structure of the product. The range of HD was found to be 11.39 to 15.89 $\mathrm{N}$ (Table 1). For HD, the regression analysis report showed that increase in the content of OF had significant positive linear effect on the extrudate (Table 3). As revealed from the response surface plot (Fig. 3), increase in DGPF and OF increased HD of the extrudate. Low HD, which is also a favourable property of extrudate, was observed at lower levels of DGPF and OF. This could be attributed to the lower expansion of products leading to increased HD as observed from expansion values, because of the high protein contents in DGPF and high dietary fibre contents in OF. Because proteins affect the LE through their ability to influence water distribution in the matrix and through their macromolecular structure and conformation that affect the extensional properties of the extruded melts (MORARU \& KOKINI, 2003). ARORA and CAMiRE (1994) reported that cookies made by replacing 10 or $15 \%$ of the oat flour with extruded potato rinds resulted in dark, hard products of smaller diameter.

\subsection{Optimization}

A numerical multi-response optimization technique of RSM was applied to determine the optimum combination of OF and DGPF for the production of extrudates using composite flour of rice and corn with a twin-screw extruder. The main criteria for constraints optimization were LE, BD, and HD. The following limits were proposed: LE was kept maximum, while $\mathrm{BD}$ and $\mathrm{HD}$ were kept minimum, and finally the desirability was 0.70 . From the numerical response analysis, it was found that optimum values were $41.91 \%$ OF and $7.93 \%$ DGPF. The product response variables resulted in the identification of a combination that satisfied all 
constraints. Finally, the optimized solution provided the ranges of variables that could be considered as the optimum range for best product quality in terms of LE, BD, and HD. These optimum conditions can be used to produce a quality extrudate.

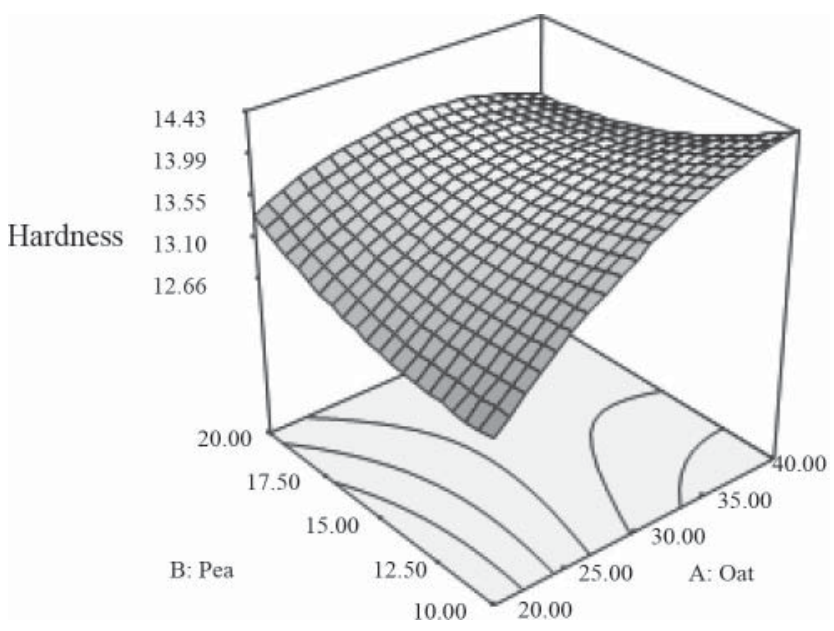

Fig. 3. Response surface plot for hardness (N) as a function of OF and DGPF

\section{Conclusions}

The product responses including LE, BD, WSI, WAI, and hardness were affected by both OF and DGPF. Blends of $41.91 \%$ OF and $7.93 \%$ DGPF had higher preference levels for parameters of physical parameters and hardness. The findings of this study investigated the feasibility of developing value added products from mixture of OF and DGPF in combination with rice and corn flour by extrusion processing.

This work was financially supported by Maulana Azad National Fellowship scheme for minority, UGC, Govt. of India.

\section{References}

Alvarez-Martinez, L., Kondury, K.P. \& Karper, J.M. (1988): A general model for expansion of extruded products. J. Food Sci., 53, 609-615.

ANDERSON, R.A. (1982): Water absorption and solubility and amylograph characteristics of roll-cooked small grain products. Cereal Chem., 59, 265-269.

AOAC (2005): Official methods of analysis of the AOAC International. 18th ed. Association of Official Analytical Chemists Gaithersburg, MD.

Arora, A. \& CAmire, M.E. (1994): Performance of potato peels in muffins and cookies. Food Res. Int., 27, 15-22.

Balasubramanian, S., Borah, A. \& Mahanta, C.L. (2012): Rheological and nutritional properties of legumes incorporated corn extrudates. Int. Food Res. J., 19, 971-975.

Chang, Y.K., Martinez-Flores, H.E., Martinez-Bustos, F. \& SGarbieri, V.C. (2002): Effect of extruded products made with cassava starch blended with oat fiber and resistant starch on the hypocholesterolemic properties as elevated in hamsters. Nutraceuticals \& Food, 7, 133-138.

Acta Alimentaria 45, 2016 
Chapuin, M.F. (2003): Fiber and water binding. Proceedings of the Nutrition Society, 62, 223-227.

FAO (2007): Protein and amino acid requirements in human nutrition. Report of joint WHO/FAO/UNU Expert consultation, WHO Technical Report Series 935.

Frias, J., Giacomino, S.E., Peñas, N., Pellegrino, V., Ferreyra, N., Apro, M., Olivera-Carrión, C. \& VidalVALVERDE (2011): Assessment of the nutritional quality of raw and extruded Pisum sativum L. var. laguna seeds. LWT - Food Sci. Technol., 44, 1303-1308.

Holguín-Acuña, A.L., Carvajal-Millán, E., Santana-Rodríguez, V., Rascón-Chu, A., Márquez-Escalante, J.A., Nora, E. Ponce De León-Renova, N.E.P. \& Gastelum-Franco, G. (2008): Maize bran/oat flour extruded breakfast cereal: A novel source of complex polysaccharides and an antioxidant. Food Chem., 111, 654-657.

Ilo, S., Tomschik, U., Berghofer, E. \& Mundigler, N. (1996): The effect of extrusion operating conditions on the apparent viscosity and the properties of extrudates in twin-screw extrusion cooking of maize grits. Food Sci. Technol., 29, 593-598.

JAMORA, J.J., RHEe, K.S. \& RHEE, K.C. (2002): Chemical and sensory properties of expanded extrudates from pork meat-defatted soy flour blends with onion, carrot and oat. J. Food Sci. Nutr., 6, 158-162.

Meng, X., Threinen, D., Hansen, M. \& Driedger, D. (2010): Effects of extrusion conditions on system parameters and physical properties of a chickpea flour-based snack. Food Res. Int., 43, 650-658.

MoraRU, C.I. \& KoKINI, J.L. (2003): Nucleation and expansion during extrusion and microwave heating of cereal foods. Comp. Rev. Food Sci. F., 2, 120-138.

Onwulata, C.I., Smith, P.W., Konstance, R.P. \& Holsinger, V.H. (2001): Incorporation of whey products in extruded corn, potato or rice snacks. Food Res. Int., 34, 679-687.

Paton, D. (1979): Oat starch: some recent developments. Stärke, 31, 184-187.

Peterson, D.M. (2001): Oat antioxidants. J. Cereal Sci., 33, 115-129.

RavindRan, G., Carr, A. \& Hardacre, A. (2011): A comparative study of the effects of three galactomannans on the functionality of extruded pea-rice blends. Food Chem., 124, 1620-1626.

Shirani, G. \& GanesharaneE, R. (2009): Extruded products with fenugreek (Trigonella foenum-graecium) chickpea and rice: Physical properties, sensory acceptability and glycaemic index. J. Food Eng., 90, 44-52.

Singh, B., Sekhon, K.S. \& Singh, N. (2007): Effects of moisture, temperature and level of pea grits on extrusion behaviour and product characteristics of rice. Food Chem., 100, 198-202.

SRIBURI, P. \& Hill, S.E. (2000): Extrusion of cassava starch with either variations in ascorbic acid concentration or pH. Int. J. Food Sci. Tech., 35, 141-154.

SudHa, M.L. \& LeeLAVATHI, K. (2012): Effect of blends of dehydrated green pea flour and amaranth seed flour on the rheological, microstructure and pasta making quality. J. Food Sci. Technol., 49, 713-720.

Wani, S.A., Shah, T.R., Bazaria, B., NayiK, G.A., Gull, A., Muzaffar, K. \& Kumar, P. (2014): Oats as a functional food: a review. Universal Journal of Pharmacy, 3(1), 14-20. 